\title{
Host-Directed Therapeutics as a Novel Approach for Tuberculosis Treatment
}

\author{
Ye-Ram Kim ${ }^{1,2}$ and Chul-Su Yang ${ }^{1,2 *}$ \\ ${ }^{1}$ Department of Molecular and Life Science, Hanyang University, Ansan 15588, Republic of Korea \\ ${ }^{2}$ Department of Bionano Technology, Hanyang University, Seoul 04673, Republic of Korea
}

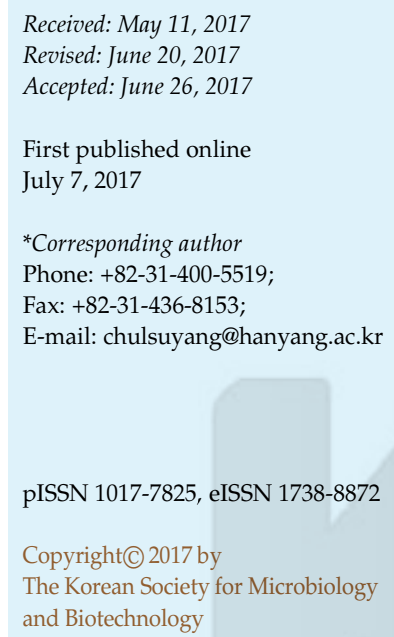

\begin{abstract}
Despite significant efforts to improve the treatment of tuberculosis (TB), it remains a prevalent infectious disease worldwide owing to the limitations of current TB therapeutic regimens. Recent work on novel TB treatment strategies has suggested that directly targeting host factors may be beneficial for TB treatment. Such strategies, termed host-directed therapeutics (HDTs), focus on host-pathogen interactions. HDTs may be more effective than the currently approved TB drugs, which are limited by the long durations of treatment needed and the emergence of drug-resistant strains. Targets of HDTs include host factors such as cytokines, immune checkpoints, immune cell functions, and essential enzyme activities. This review article discusses examples of potentially promising HDTs and introduces novel approaches for their development.
\end{abstract}

Keywords: Tuberculosis, Mycobacterium tuberculosis, multidrug resistance, host-directed therapeutics, immunomodulatory regulator

\section{Introduction}

Tuberculosis (TB), which is caused by infection with Mycobacterium tuberculosis (MTB), is a global health problem with significant lethality [1]. In 2015, 10.4 million people were infected with TB, and 1.8 million people died because of the disease, including 0.4 million people who were coinfected with human immunodeficiency virus (HIV). This is significant because in that same year, $35 \%$ of HIVrelated deaths were caused by TB. In 2015, approximately 480,000 people had multidrug-resistant TB (MDR-TB), and $9 \%$ of TB patients were infected with an MTB strain that was classified as extensively drug-resistant TB (XDR-TB). Treatment of these resistant strains requires a considerably long duration, with toxic side effects and at a great expense [2]. For the past 40 years, TB therapy has used a combination of effective anti-TB drugs to manage active infections. Generally, TB needs to be treated for 6 months and XDR-TB for 12-18 months. Furthermore, the current therapy for XDR-TB is effective in only $50 \%$ of cases and imposes a severe financial burden on patients [3]. Current anti-TB drugs have other limitations such as adverse effects and interactions with other drugs [4]. In addition, patients experience abnormal host inflammatory responses caused by permanent lung tissue damage [5]. Therefore, novel therapeutic strategies are required to treat these difficult TB cases. One novel approach, termed host-directed therapeutics (HDTs), involves directly targeting host factors rather than pathogen components [6]. HDTs also reduce pathogen proliferation and the hyperinflammatory response by modulating the host immune system [7]. HDTs have improved clinical outcomes with reduced morbidity, mortality, organ damage, and TB therapy duration.

\section{Current Anti-TB Drugs}

Treatment with first-line anti-TB drugs (Table 1) is a twostep process that was developed from 1950 to 1960; treatment lasts for at least 6 months [8]. The first step is an intensive treatment over 2 months with four first-line drugs: isoniazid (4-pyridinecarboxylic acid hydrazide, INH), rifampicin, pyrazinamide, and ethambutol. The second step is 4 months long and involves continuous isoniazid and rifampicin administration (short-course chemotherapy) [9]. 
Table 1. Current drugs for treatment of tuberculosis (TB).

\begin{tabular}{|c|c|c|c|c|}
\hline \multirow{2}{*}{$\begin{array}{l}\text { Classification } \\
\text { First-line } \\
\text { anti-TB drugs }\end{array}$} & \multirow{2}{*}{$\begin{array}{l}\text { Drug name } \\
\text { Isoniazid }\end{array}$} & \multirow{2}{*}{$\begin{array}{c}\text { Year of discovery } \\
1952\end{array}$} & Group & \multirow[t]{2}{*}{ Structure } \\
\hline & & & Group1 : Oral & \\
\hline & Rifampicin & 1963 & & \\
\hline & Pyrazinamide & 1954 & & \\
\hline & Ethambutol & 1961 & & \\
\hline \multirow[t]{6}{*}{$\begin{array}{l}\text { Second-line } \\
\text { anti-TB drugs }\end{array}$} & Streptomycin & 1944 & $\begin{array}{l}\text { Group 2: } \\
\text { Injectable aminoglycosides }\end{array}$ & \\
\hline & Kanamycin & 1957 & & \\
\hline & Amikacin & 1972 & & \\
\hline & Capreomycin & 1963 & $\begin{array}{l}\text { Group 2: } \\
\text { Injectable polypeptides }\end{array}$ & \\
\hline & Viomycin & 1951 & & \\
\hline & Ciprofloxacin & 1961 & Group 3 : & \\
\hline
\end{tabular}


Table 1. Continued.

\begin{tabular}{|c|c|c|c|c|}
\hline \multirow{2}{*}{$\begin{array}{l}\text { Classification } \\
\text { Second-line } \\
\text { anti-TB drugs }\end{array}$} & \multirow{2}{*}{$\begin{array}{l}\text { Drug name } \\
\text { Levofloxacin }\end{array}$} & \multirow{2}{*}{$\begin{array}{c}\text { Year of discovery } \\
1987\end{array}$} & \multirow{2}{*}{$\begin{array}{l}\text { Group } \\
\text { Group 3: } \\
\text { Oral and injectable fluoroquinolones }\end{array}$} & \multirow[t]{2}{*}{ Structure } \\
\hline & & & & \\
\hline & Moxifloxacin & 1988 & & \\
\hline & Ofloxacin & 1980 & & \\
\hline & Gatifloxacin & 1992 & & \\
\hline & Para-aminosalicylic acid & 1948 & Group 4 : Oral & \\
\hline & Cycloserine & 1954 & & \\
\hline & Terizidone & 1965 & & \\
\hline & Ethionamide & 1961 & & \\
\hline & Prothionamide & 1956 & & \\
\hline & Thioacetazone & 1951 & & \\
\hline & Linezolid & 1996 & & \\
\hline
\end{tabular}

Anti-TB drugs are categorized by evidence of efficacy, potency, and case of use.

INH targets an enoyl-(acyl-carrier-protein) reductase and inhibits mycolic acid synthesis; it is a prodrug that requires activation by the catalase-peroxidase enzyme KatG [10]. Pyrazinamide inhibits translation by inhibiting the $30 \mathrm{~S}$ ribosomal S1 component [11]. First-line drugs such as INH and pyrazinamide contribute to host defenses against MTB by triggering the formation of cellular and mitochondrial reactive oxygen species (ROS) and activating autophagy, which reduces the MTB-induced proinflammatory response in macrophages [12, 13]. Ethambutol targets arabinosyl transferase, which blocks arabinogalactan biosynthesis [14]. Although these first-line drugs initially show anti-TB 
effects, they have several limitations. These TB treatment regimens are lengthy, involve drug intolerance and toxicity, and require the consideration of pharmacokinetic drug-drug interactions, particularly with anti-HIV drugs for patients with HIV coinfection [4]. The development of an improved TB therapeutic approach that is shorter, more effective against resistant strains, and has fewer drug interactions is needed [15]. Drug resistance to MTB is typically caused by inappropriate treatment of active TB infections [16].

MDR-TB is characterized by resistance to isoniazid and rifampicin. XDR-TB is defined as TB that is resistant to both isoniazid and rifampicin, as well as to any fluoroquinolone and at least one of the second-line injectable drugs (capreomycin, kanamycin, and amikacin) [17]. A World Health Organization TB treatment report has recommended treating MDR/XDR-TB using a combination of four or more antiTB drugs that are effective against MTB [18].

Second-line anti-TB drugs are used to treat MTB infections that are resistant to first-line drugs (Table 1: Groups 2, 3, and 4). Group 2 contains injectable anti-TB drugs. Streptomycin is an aminoglycoside antibiotic, derived from the soil microorganism Streptomyces griseus, which is used to treat many bacterial infectious diseases, including TB [2]. This drug was the first antibiotic used against TB. Streptomycin interacts directly with the $12 \mathrm{~S}$ and $16 \mathrm{~S}$ rRNA components of the $30 \mathrm{~S}$ ribosomal subunit, thus inhibiting protein synthesis [19]. Unfortunately, the use of this antibiotic led to the rapid emergence of a resistant strain [20]. Because many MDR-TB patients have resistance to streptomycin, it is not commonly used for treating MDR-TB [21]. Second-line anti-TB drugs such as kanamycin, amikacin, capreomycin, and viomycin target protein synthesis. Kanamycin and amikacin are aminoglycosides and target the $30 \mathrm{~S}$ ribosomal subunit [22]. Capreomycin and viomycin are cyclic peptide antibiotics with similar structures that bind at the same site on the ribosome. They target the interface between the $30 \mathrm{~S}$ and $50 \mathrm{~S}$ ribosomal subunits. However, Group 2 drugs also cause several adverse effects such as ototoxicity, neurotoxicity, nephrotoxicity, and hypersensitivity. In particular, aminoglycosides may act as neuromuscular blocking agents, leading to respiratory failure [23]. Group 3, composed of fluoroquinolones, inhibits topoisomerase II (DNA gyrase), topoisomerase IV, and MTB topoisomerase II [24]. The side effects of fluoroquinolones occur mainly in the gastrointestinal tract, and $3-17 \%$ of patients treated with fluoroquinolones experience these side effects [23]. Group 4, oral bacteriostatic second-line anti-TB drugs, includes paraamino salicylic acid (PAS), cycloserine, ethionamide, and linezolid. PAS targets dihydropteroate synthase, causing it to inhibit folate biosynthesis and iron uptake [25]. Common adverse effects of PAS include nausea, pain, and diarrhea. PAS can also cause liver inflammation and other allergic reactions [26]. Cycloserine, a D-alanine analog, inhibits peptidoglycan synthesis [27] and can have neurological and psychiatric side effects. [23] Ethionamide is a potent drug used to treat MDR-TB, and its structure is similar to that of isoniazid. It is also a prodrug that requires activation by a monooxygenase encoded by the ethA gene [28]. Similar to isoniazid, ethionamide targets an enoyl-(acyl-carrierprotein) reductase and inhibits mycolic acid biosynthesis [29]. It can also lead to adverse effects in the gastrointestinal tract, along with hepatotoxicity, neurotoxicity, cardiovascular effects, and endocrine effects [23]. Linezolid (Zyon) is a representative drug for eradicating resistant strains. Linezolid was approved for use against drug-resistant, gram-positive bacteria in the 2000s [30]. It is a member of the oxazolidinone antibiotic class, and inhibits protein synthesis by interfering with the functioning of the 23S rRNA. In addition, linezolid has in vitro antibacterial activity against MTB, including against MDR and XDR strains [31]. Moreover, linezolid had an effect on XDR strains in a study on pulmonary-TB patients [32] (Table 1). Linezolid therapy can last for less than 28 days and has mild side effects. This drug affects the nervous, gastrointestinal, hematologic, hepatic, and metabolic systems [33]. Second-line anti-TB drugs, which are used to treat infections resulting from a first-line drug-resistant strain, have also led to the development of resistant MTB strains. A spontaneous mutation in a MTB gene targeted by a current TB drug can result in drug resistance.

\section{The Need for Novel TB Drugs}

New drugs for treating MDR-/XDR-TB would ideally have a novel mechanism of action to circumvent the current drug resistance. Lower toxicity drugs could reduce side effects during TB treatment. The period of treatment, which imposes a considerable economic burden and is associated with the risk of the development of antibioticresistant strains, also needs to be shortened. To shorten the treatment period, novel drugs should have potent bactericidal activity against most types of MTB. Novel drugs should be effective and safe, and a low dosage frequency would also be promising. Therefore, the development of dose formulations and delivery technologies is another requirement for more advanced TB treatment. Effective drug combination regimens can also reduce the number of pills required [17]. 


\section{Host-Directed Therapies}

HDTs for managing TB are composed of two main strategies: enhancing the antimicrobial activity to clear pathogens, and controlling excess inflammation to prevent permanent lung tissue damage. Current HDTs can potentially inhibit TB development via diverse host pathways, such as signal transduction-mediating cytokines, antimicrobial processes, immune cell regulation, and epigenetic modulation [34]. The use of HDTs can be expected to reduce the bacterial burden and fine-tune the host inflammatory response. HDTs may also require minimal doses and short treatment durations and may be used in combination with existing drugs to enhance their overall effect.

Next, this review introduces several representative HDTs for the treatment of TB (listed in Table 2) [34].

(1) Metformin (Glucophage), which acts as an autophagy inducer, is currently approved for the treatment of type 2 diabetes. Many studies have shown that the activation of autophagy leads to the clearance of MTB [35]. Metformin activates adenosine monophosphate-activated protein kinases, which are sensors of cellular energy levels [36]. Targeting adenosine monophosphate-activated protein kinases is predicted to be a potential anti-TB treatment [37]. Metformin inhibits MTB growth by inducing mitochondrial ROS production in vitro. The effect of current anti-TB drugs can be enhanced by metformin, which was confirmed in both acute and chronic TB mouse models. Furthermore, metformin reduced the TB-mediated tissue pathology and enhanced interferon (IFN)- $\gamma$-secreting CD8+ and CD4+

Table 2. Development of host-directed therapeutics for tuberculosis.

\begin{tabular}{|c|c|c|c|c|c|}
\hline Category & Name & $\begin{array}{l}\text { Currently approved } \\
\text { indication(s) }\end{array}$ & Host target & $\begin{array}{l}\text { Developmental } \\
\text { stage }\end{array}$ & Ref. \\
\hline \multirow[t]{4}{*}{$\begin{array}{l}\text { Repurposed } \\
\text { drug }\end{array}$} & Imatinib & $\begin{array}{l}\text { Leukemia and gastrointestinal } \\
\text { stromal tumors }\end{array}$ & Tyrosine kinase & $\begin{array}{l}\text { Preclinical/clinical } \\
\text { (early phase) }\end{array}$ & [39] \\
\hline & Verapamil & $\begin{array}{l}\text { High blood pressure, } \\
\text { chest pain and supraventricular } \\
\text { tachycardia }\end{array}$ & $\begin{array}{l}\text { Voltage-dependent } \\
\text { calcium channels }\end{array}$ & & [34] \\
\hline & Metformin & Diabetes & $\begin{array}{l}\text { AMP-activated protein } \\
\text { kinase activator }\end{array}$ & & [38] \\
\hline & Ibuprofen & Pain and fever relief & Cyclooxygenase inhibitor & & [41] \\
\hline \multirow{3}{*}{$\begin{array}{l}\text { Cytokine } \\
\text { therapy }\end{array}$} & IL-2 & Renal cancer and melanoma & Cytokine modulation & Clinical & [53] \\
\hline & GM-CSF & $\begin{array}{l}\text { Acute myelogenous leukemia, } \\
\text { after bone marrow } \\
\text { transplantation }\end{array}$ & Cytokine modulation & (late phase) & [64] \\
\hline & IFN- $\gamma$ & Chronic granulomatous disease & Cytokine modulation & & {$[65]$} \\
\hline \multirow{3}{*}{$\begin{array}{l}\text { Monoclonal } \\
\text { antibody }\end{array}$} & Adalimumab (Anti-TNF $\alpha$ ) & Rheumatoid arthritis & Cytokine neutralization & Preclinical/ & [54] \\
\hline & Tocilizumab (Anti-IL6R) & $\begin{array}{l}\text { Juvenile arthritis, } \\
\text { Castleman's disease }\end{array}$ & Cytokine neutralization & $\begin{array}{l}\text { clinical } \\
\text { (early phase) }\end{array}$ & [56] \\
\hline & Bevacizumav (Anti-VEGF) & Various cancer types & Angiogenesis inhibitor & & [57] \\
\hline \multirow[t]{3}{*}{$\begin{array}{l}\text { Monoclonal } \\
\text { antibody }\end{array}$} & $\begin{array}{l}\text { Nivolumab } \\
\text { /pembrolizumab (Anti-PD-1) }\end{array}$ & $\begin{array}{l}\text { Melanoma, } \\
\text { various other cancers }\end{array}$ & $\begin{array}{l}\text { Immune checkpoint } \\
\text { inhibitor }\end{array}$ & Preclinical & [45] \\
\hline & Anti-LAG3 & Various cancers & $\begin{array}{l}\text { Immune checkpoint } \\
\text { inhibitor }\end{array}$ & & {$[66]$} \\
\hline & Ipilimumab (Anti-CTLA-4) & $\begin{array}{l}\text { Melanoma, } \\
\text { various other cancers }\end{array}$ & $\begin{array}{l}\text { Immune checkpoint } \\
\text { inhibitor }\end{array}$ & & [67] \\
\hline Vitamin & Vitamin $\mathrm{D}_{3}$ & Dietary supplement & $\begin{array}{l}\text { Innate immune response } \\
\text { activator }\end{array}$ & $\begin{array}{l}\text { Clinical } \\
\text { (late phase) }\end{array}$ & [44] \\
\hline \multirow[t]{2}{*}{$\begin{array}{l}\text { Cellular } \\
\text { therapy }\end{array}$} & $\begin{array}{l}\text { Bone marrow-derived } \\
\text { mesenchymal stromal cells }\end{array}$ & $\begin{array}{l}\text { Various inflammatory } \\
\text { indications }\end{array}$ & $\begin{array}{l}\text { Reduction of inflammation } \\
\text { and enhancement of tissue } \\
\text { regeneration }\end{array}$ & $\begin{array}{l}\text { Clinical } \\
\text { (late phase) }\end{array}$ & {$[68]$} \\
\hline & Antigen-specific T cells & Cancer and viral infections & $\begin{array}{l}\text { Targeted killing of } \\
\text { MTB-infected host cells }\end{array}$ & & {$[68]$} \\
\hline
\end{tabular}


T-cell populations. It also reduced the activity of chronic inflammatory genes in TB patients, in addition to reducing mortality [38].

(2) Imatinib mesylate (Gleevec) is used to treat leukemia and gastrointestinal stromal tumors. Imatinib is a smallmolecule kinase inhibitor that blocks tyrosine kinase enzymes. The therapeutic administration of imatinib promotes the acidification and maturation of MTB-infected macrophage phagosomes, reducing the number of colonyforming units (CFUs) in MTB-infected mice. Furthermore, imatinib works synergistically with first-line anti-TB drugs to inhibit drug-resistant mycobacterial strains. At subtherapeutic concentrations, imatinib strengthens host defenses by increasing neutrophil and monocyte numbers through myeloproliferation $[39,40]$.

(3) Ibuprofen (Advil, Motrin, Nurofen) is a non-steroidal anti-inflammatory drug normally used as a painkiller and an antipyretic. This inhibitor of cyclooxygenase inhibits prostaglandin $\mathrm{E}_{2}$ production and enhances tumor necrosis factor (TNF) production in macrophages. Although the direct antimycobacterial activity of ibuprofen is not potent, it reduces lung tuberculous lesions and bacterial burden and enhances the survival rate in a mouse model that mimics active TB [41].

(4) Zileuton (ZYFLO) is a 5-lipooxygenase inhibitor that inhibits the formation of leukotrienes (LTB4, LTC4, LTD4, and LTE4) and has been approved to treat asthma. Mice and humans infected with MTB show decreased IL-1 responses and increased production of type I IFN, resulting in an eicosanoid imbalance that causes severe TB. Zileuton reduces weight loss and the number of CFUs and protects against acute mortality by increasing prostaglandin $\mathrm{E}_{2}$ levels [42].

(5) Vitamin $D_{3}$ is a dietary supplement that activates the innate immune response. Low vitamin $\mathrm{D}_{3}$ levels are involved in the development of active TB. Vitamin $\mathrm{D}_{3}$ has an important role in converting $2,5(\mathrm{OH}) \mathrm{D}$ into $1,25-(\mathrm{OH})_{2} \mathrm{D}_{3}$, which is its active form. This active form induces the production of cathelicidin, which is an antimicrobial peptide. After MTB infection, macrophages produce cathelicidin through Toll-like receptor signaling; thus, vitamin D can indirectly inhibit MTB [43]. Treatment with both vitamin $\mathrm{D}_{3}$ and 4-phenyl butyrate synergistically enhances cathelicidin production [44].

(6) Another potent target of HDTs is immune checkpoints. These immunomodulatory therapeutic strategies have been studied extensively in cancer research. Programmed cell death 1 (PD-1) is a protein on the surface of active T cells. When programmed death-ligand 1 (PD-L1) and PD-L2 associate with PD-1 on the T-cell surface, $\mathrm{T}$ cells cannot attack other cells. Nivolumab and pembrolizumab are PD-1 inhibitors currently used to treat melanomas and other cancers. Antigen-specific IFN- $\gamma$ was rescued using a PD-1 inhibitor in TB patients, confirming that nivolumab/ pembrolizumab has potential in treating TB [45]. Cytotoxic T-lymphocyte-associated protein 4 affects immune checkpoints, and it is expressed in active TB patients. Antigen-specific lymphocyte expansion and cytokine expression can be increased by blocking cytotoxic T-lymphocyte-associated protein 4 [46].

(7) Cytokine therapy could be an alternative method to limit the currently used TB chemotherapy. This method uses immunomodulators to boost the immune system [47]. Cytokines contribute to various cellular responses, including immune signaling in TB. Cytokine therapy induces a proinflammatory immune response and antimicrobial activity, which can be beneficial in treating TB. IFN- $\gamma$ plays a major role in the host defenses against MTB. IFN- $\gamma$, as a prototypical product of Th1 cells, promotes the secretion of Th1 cytokines (such as IL-12) and inhibits Th2 cytokines (such as IL-4). In addition, IFN- $\gamma$ upregulates class I and II antigen-presenting cells and increases the antimicrobial activity of macrophages. Mutations in the IFN- $\gamma$ receptor gene result in high susceptibility to mycobacterial infections [48]. Granulocyte macrophage colony-stimulating factor (GM-CSF) increases the number of macrophages, leading to an enhanced inflammatory response. GM-CSF also shows antimycobacterial activity in human macrophages [49]. Studies on GM-CSF-deficient mice showed that GM-CSF plays critical immunomodulatory roles in the host defenses against pulmonary TB [50]. Moreover, IL-2 induces the expansion of $\mathrm{T}$ cells. However, recent studies have shown that IL-2 promotes CD4+CD25+ regulatory T-cell expansion, which suppresses the T-cell response [51]. Some clinical trials testing the effectiveness of IL-2 against TB have been reported $[52,53]$.

Excessive proinflammatory cytokine production causes permanent host tissue damage. Therefore, regulating cytokine production could be an alternative approach to treat TB by reducing destructive inflammation. The current monoclonal antibody used for cytokine neutralization modulates inflammatory responses. The anti-TNF therapeutic agent adalimumab has been previously used to treat TB [54]. IL-6, which accelerates the severity of disease in TB patients, is a promising candidate. Blockage of the IL-6/IL-6 receptor pathway is considered therapeutic in treating various diseases [55]. The use of a monoclonal antibody, along with the IL-6 receptor blockage, enhances anti-TB 
T-cell responses, decreases severe pathology, and reduces the MTB burden in mice [56]. The anti-vascular endothelial growth factor (anti-VEGF, bevacizumab) monoclonal antibody inhibits TB by normalizing vasculature, increasing the delivery of small molecules, and decreasing hypoxia in tuberculous granulomas [57]. Therefore, the anti-VEGF monoclonal antibody may increase the efficacy of current treatment regimens.

Cell-based therapies are considered effective alternative therapies in treating cancer and infectious diseases. In addition, such therapies might decrease tissue-destructive inflammation, enhance organ repair, and intensify antigenspecific immune responses [58].

Several studies have focused on immunomodulatory functions that show antimycobacterial activity [59-61]. Previously, we developed a novel treatment strategy for treating an intracellular parasite infection, which might be used as an HDT strategy against TB. We investigated interactions between the intracellular parasite Toxoplasma gondii and host macrophages and clarified the cellular signaling involved in this interaction. T. gondii dense granule antigen (GRA) 7 is essential for the innate immune response and acts through an association with TNF receptorassociated factor 6 (TRAF6) via myeloid differentiation primary response gene 88 . The interaction between GRA7 and TRAF6 confers a protective effect against $T$. gondii infection in vivo [62]. We performed further experiments to determine whether GRA7 modulation of the innate immune response could work for other infectious diseases such as TB. We found that GRA7 interacted with many host proteins, including important host immune response regulators. We showed that the protein kinase $\mathrm{C}$ alphamediated phosphorylation of GRA7 is essential for the interaction between apoptosis-associated speck-like protein

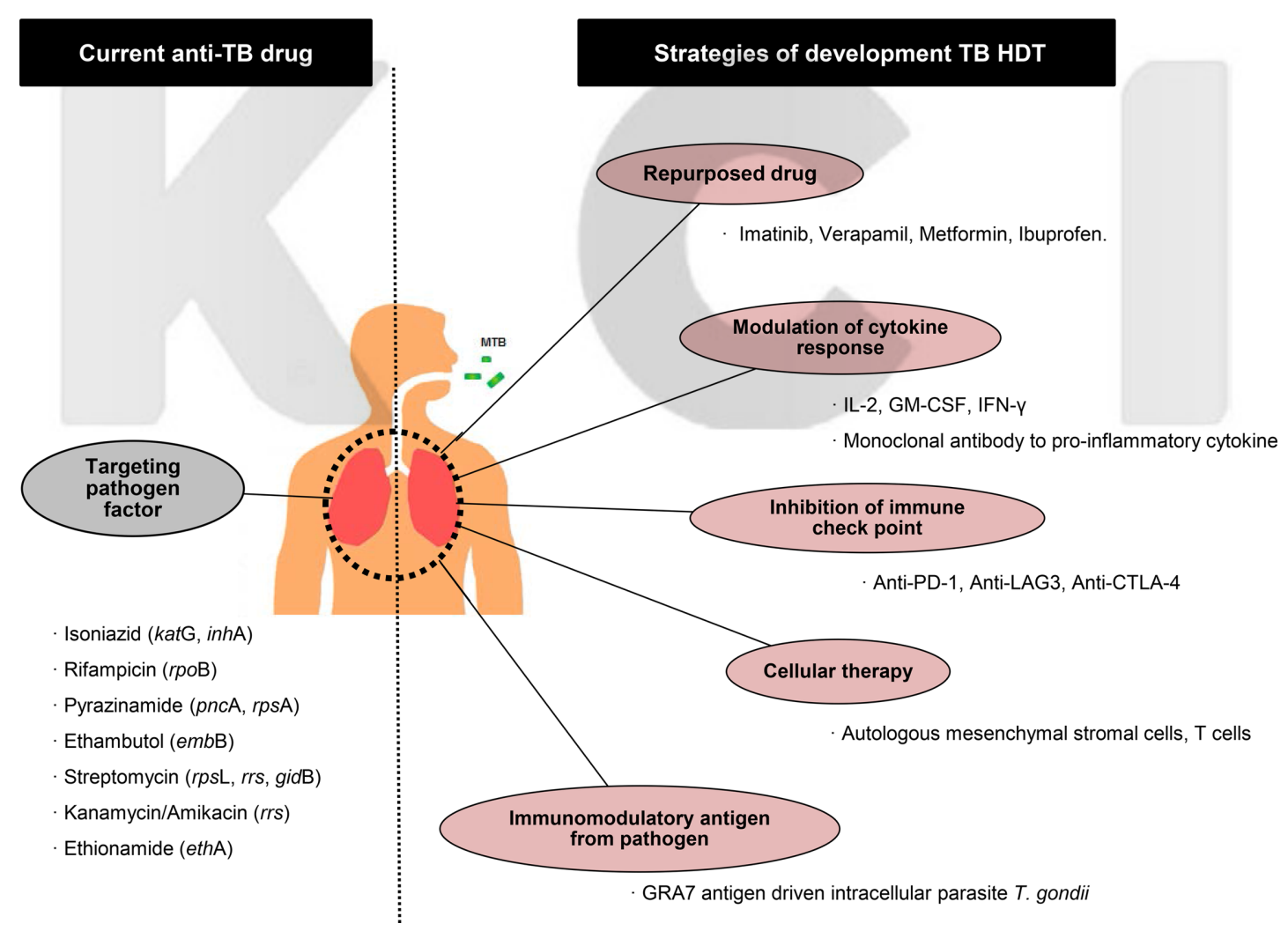

Fig. 1. Comparison between current anti-tuberculosis (TB) drugs and potential host-directed therapeutic (HDT) strategies for treating TB.

Current anti-TB drugs have been developed by targeting pathogenic factors such as bacterial proliferation. A spontaneous mutation in one of the genes that is targeted by these antibiotics can lead to the emergence of drug-resistant TB strains. To overcome the limitations of current anti-TB drugs, the development of new drugs is necessary. HDTs directly affect host factors. Strategies for developing anti-TB HDTs have been verified in several TB studies. IL-2, Interleukin-2; GM-CSF, Granulocyte macrophage colony-stimulating factor; IFN- $\gamma$, Interferon gamma; PD-1, Programmed cell death protein 1, LAG3, Lymphocyte activation gene 3; CTLA-4, Cytotoxic T-lymphocyte-associated antigen 4; GRA7, Toxoplasma gondii dense granule antigen 7 . 
containing a carboxyl-terminal CARD and phospholipase D1. These interactions induced antibacterial activity against TB. GRA7 controlled the innate immune response by interacting with host cell proteins. Our current studies have established proof of concept for developing novel HDT strategies that could serve as alternatives to treat TB [63] (Fig. 1).

In conclusion, by directly targeting host factors, HDTs enhance immune responses and fine-tune inflammation, and can thus be used to treat bacterial, viral, and parasitic infectious diseases. Current treatment for MTB-mediated TB has several limitations, including the long period of treatment, emergence of resistant strains, and toxicity of the drugs. These limitations increase the need for developing novel TB treatment strategies. The present review focused on potential novel HDTs that may be used to treat TB. HDTs play a role in the clearance of MTB and regulation of excess inflammatory responses to protect the host from permanent organ damage. Furthermore, the combination of HDTs with current TB drugs reduces drug dosages and improves clinical outcomes. HDTs can be used to target many pathways, and as such can be used to verify the antimycobacterial activity of an approved drug (re-purposed drugs), inhibit immune checkpoints, and modulate cytokine production. We have shown that antigens derived from the intracellular parasite $T$. gondii modulate the immune response and might be promising for treating MBT infection. However, the potential uses of HDTs need to be explored further. Because HDTs directly interact with host factors, various factors need to be considered prior to their application. Furthermore, it is difficult to establish HDTs that manipulate a human factor using animal models. Because HDTs target complex pathways, there should be detailed investigations into the potential side effects of HDTs. Understanding the host immune response in TB-mediated immune pathology is very important in HDT research.

\section{Acknowledgments}

This work was supported by a research fund of Hanyang University (HY-2014-N).

\section{Conflict of Interest}

The authors have no financial conflicts of interest to declare.

\section{References}

1. Zaman K. 2010. Tuberculosis: a global health problem. J.
Health Popul. Nutr. 28: 111-113.

2. World Health Organization. 2016. Global Tuberculosis Report 2016. WHO, Geneva, Switzerland.

3. Schnippel K, Rosen S, Shearer K, Martinson N, Long L, Sanne I, et al. 2013. Costs of inpatient treatment for multidrug-resistant tuberculosis in South Africa. Trop. Med. Int. Health 18: 109-116.

4. Arbex MA, Varella Mde C, Siqueira HR, Mello FA. 2010. Antituberculosis drugs: drug interactions, adverse effects, and use in special situations. Part 1: first-line drugs. J. Bras. Pneumol. 36: 626-640.

5. Zumla A, Rao M, Parida SK, Keshavjee S, Cassell G, Wallis R, et al. 2015. Inflammation and tuberculosis: host-directed therapies. J. Intern. Med. 277: 373-387.

6. Hawn TR, Matheson AI, Maley SN, Vandal O. 2013. Hostdirected therapeutics for tuberculosis: can we harness the host? Microbiol. Mol. Biol. Rev. 77: 608-627.

7. Zumla A, Maeurer M, Host-Directed Therapies Network, Chakaya J, Hoelscher M, Ntoumi F, et al. 2015. Towards host-directed therapies for tuberculosis. Nat. Rev. Drug Discov. 14: 511-512.

8. World health Organization, Initiative ST. 2010. Treatment of Tuberculosis: Guidelines. WHO, Geneva, Switzerland.

9. D'Ambrosio L, Centis R, Sotgiu G, Pontali E, Spanevello A, Migliori GB. 2015. New anti-tuberculosis drugs and regimens: 2015 update. ERJ Open Res. 1: 00010-2015.

10. Timmins GS, Deretic V. 2006. Mechanisms of action of isoniazid. Mol. Microbiol. 62: 1220-1227.

11. Shi W, Zhang X, Jiang X, Yuan H, Lee JS, Barry CE 3rd, et al. 2011. Pyrazinamide inhibits trans-translation in Mycobacterium tuberculosis. Science 333: 1630-1632.

12. Kim JJ, Lee HM, Shin DM, Kim W, Yuk JM, Jin HS, et al. 2012. Host cell autophagy activated by antibiotics is required for their effective antimycobacterial drug action. Cell Host Microbe 11: 457-468.

13. Zullo AJ, Lee S. 2012. Old antibiotics target TB with a new trick. Cell Host Microbe 11: 419-420.

14. Kolyva AS, Karakousis PC. 2012. Old and New TB Drugs: Mechanisms of Action and Resistance. INTECH Open Access Publisher, Croatia.

15. Zumla A, Nahid P, Cole ST. 2013. Advances in the development of new tuberculosis drugs and treatment regimens. Nat. Rev. Drug Discov. 12: 388-404.

16. Rattan A, Kalia A, Ahmad N. 1998. Multidrug-resistant Mycobacterium tuberculosis: molecular perspectives. Emerg. Infect. Dis. 4: 195.

17. Lange C, Abubakar I, Alffenaar JW, Bothamley G, Caminero JA, Carvalho AC, et al. 2014. Management of patients with multidrug-resistant/extensively drug-resistant tuberculosis in Europe: a TBNET consensus statement. Eur. Respir. J. 44: 23-63.

18. World health Organization. 2011. Guidelines for the Programmatic Management of Drug-resistant Tuberculosis - 2011 Update. WHO, Geneva, Switzerland. 
19. Sharma D, Cukras AR, Rogers EJ, Southworth DR, Green R. 2007. Mutational analysis of S12 protein and implications for the accuracy of decoding by the ribosome. J. Mol. Biol. 374: 1065-1076.

20. Crofton J, Mitchison D. 1948. Streptomycin resistance in pulmonary tuberculosis. Br. Med. J. 2: 1009.

21. Rich M. 2003. The PIH Guide to the Medical Management of Multidrug-resistant Tuberculosis. International Ed., Partners in Health, Boston, MA.

22. Salian S, Matt T, Akbergenov R, Harish S, Meyer M, Duscha S, et al. 2012. Structure-activity relationships among the kanamycin aminoglycosides: role of ring I hydroxyl and amino groups. Antimicrob. Agents Chemother. 56: 6104-6108.

23. Arbex MA, Varella Mde C, Siqueira HR, Mello FA. 2010. Antituberculosis drugs: drug interactions, adverse effects, and use in special situations. Part 2: second line drugs. J. Bras. Pneumol. 36: 641-656.

24. Aubry A, Pan XS, Fisher LM, Jarlier V, Cambau E. 2004. Mycobacterium tuberculosis DNA gyrase: interaction with quinolones and correlation with antimycobacterial drug activity. Antimicrob. Agents Chemother. 48: 1281-1288.

25. Wade MM, Zhang Y. 2004. Mechanisms of drug resistance in Mycobacterium tuberculosis. Front. Biosci. 9: 975-994.

26. Das KM, Eastwood MA, McManus JP, Sircus W. 1973. Adverse reactions during salicylazosulfapyridine therapy and the relation with drug metabolism and acetylator phenotype. N. Engl. J. Med. 289: 491-495.

27. Caceres NE, Harris NB, Wellehan JF, Feng Z, Kapur V, Barletta RG. 1997. Overexpression of the D-alanine racemase gene confers resistance to D-cycloserine in Mycobacterium smegmatis. J. Bacteriol. 179: 5046-5055.

28. Baulard AR, Betts JC, Engohang-Ndong J, Quan S, McAdam RA, Brennan PJ, et al. 2000. Activation of the pro-drug ethionamide is regulated in mycobacteria. J. Biol. Chem. 275: 28326-28331.

29. Carette X, Blondiaux N, Willery E, Hoos S, Lecat-Guillet N, Lens Z, et al. 2012. Structural activation of the transcriptional repressor EthR from Mycobacterium tuberculosis by single amino acid change mimicking natural and synthetic ligands. Nucleic Acids Res. 40: 3018-3030.

30. Bouza E, Munoz P. 2001. Linezolid: pharmacokinetic characteristics and clinical studies. Clin. Microbiol. Infect. 7 Suppl 4: 75-82.

31. Tato M, de la Pedrosa EG, Canton R, Gomez-Garcia I, Fortun J, Martin-Davila P, et al. 2006. In vitro activity of linezolid against Mycobacterium tuberculosis complex, including multidrug-resistant Mycobacterium bovis isolates. Int. J. Antimicrob. Agents 28: 75-78.

32. Lee M, Lee J, Carroll MW, Choi H, Min S, Song $\mathrm{T}$, et al. 2012. Linezolid for treatment of chronic extensively drugresistant tuberculosis. N. Engl. J. Med. 367: 1508-1518.

33. Watkins RR, Lemonovich TL, File TM Jr. 2012. An evidencebased review of linezolid for the treatment of methicillinresistant Staphylococcus aureus (MRSA): place in therapy.
Core Evid. 7: 131-143.

34. Zumla A, Rao M, Dodoo E, Maeurer M. 2016. Potential of immunomodulatory agents as adjunct host-directed therapies for multidrug-resistant tuberculosis. BMC Med. 14: 89.

35. Bento CF, Empadinhas N, Mendes V. 2015. Autophagy in the fight against tuberculosis. DNA Cell Biol. 34: 228-242.

36. Hur KY, Lee MS. 2015. New mechanisms of metformin action: focusing on mitochondria and the gut. J. Diabetes Investig. 6: 600-609.

37. Yang CS, Kim JJ, Lee HM, Jin HS, Lee SH, Park JH, et al. 2014. The AMPK-PPARGC1A pathway is required for antimicrobial host defense through activation of autophagy. Autophagy 10: 785-802.

38. Singhal A, Jie L, Kumar P, Hong GS, Leow MK, Paleja B, et al. 2014. Metformin as adjunct antituberculosis therapy. Sci. Transl. Med. 6: 263ra159.

39. Napier RJ, Rafi W, Cheruvu M, Powell KR, Zaunbrecher MA, Bornmann $\mathrm{W}$, et al. 2011. Imatinib-sensitive tyrosine kinases regulate mycobacterial pathogenesis and represent therapeutic targets against tuberculosis. Cell Host Microbe 10: 475-485.

40. Bruns H, Stegelmann F, Fabri M, Dohner K, van Zandbergen G, Wagner M, et al. 2012. Abelson tyrosine kinase controls phagosomal acidification required for killing of Mycobacterium tuberculosis in human macrophages. J. Immunol. 189: 4069-4078.

41. Vilaplana C, Marzo E, Tapia G, Diaz J, Garcia V, Cardona PJ. 2013. Ibuprofen therapy resulted in significantly decreased tissue bacillary loads and increased survival in a new murine experimental model of active tuberculosis. J. Infect. Dis. 208: 199-202.

42. Mayer-Barber KD, Andrade BB, Oland SD, Amaral EP, Barber DL, Gonzales J, et al. 2014. Host-directed therapy of tuberculosis based on interleukin-1 and type I interferon crosstalk. Nature 511: 99-103.

43. Chun RF, Adams JS, Hewison M. 2011. Immunomodulation by vitamin D: implications for TB. Expert Rev. Clin. Pharmacol. 4: 583-591.

44. Mily A, Rekha RS, Kamal SM, Arifuzzaman AS, Rahim Z, Khan L, et al. 2015. Significant effects of oral phenylbutyrate and vitamin D3 adjunctive therapy in pulmonary tuberculosis: a randomized controlled trial. PLoS One 10: e0138340.

45. Singh A, Mohan A, Dey AB, Mitra DK. 2013. Inhibiting the programmed death 1 pathway rescues Mycobacterium tuberculosis-specific interferon gamma-producing $\mathrm{T}$ cells from apoptosis in patients with pulmonary tuberculosis. $J$. Infect. Dis. 208: 603-615.

46. Grosso JF, Jure-Kunkel MN. 2013. CTLA-4 blockade in tumor models: an overview of preclinical and translational research. Cancer Immun. 13: 5.

47. Rivero-Lezcano OM. 2008. Cytokines as immunomodulators in tuberculosis therapy. Recent Pat. Antiinfect. Drug Discov. 3: $168-176$.

48. Ottenhoff TH, Verreck FA, Hoeve MA, van de Vosse E. 
2005. Control of human host immunity to mycobacteria. Tuberculosis 85: 53-64.

49. Denis M, Ghadirian E. 1990. Granulocyte-macrophage colonystimulating factor restricts growth of tubercle bacilli in human macrophages. Immunol. Lett. 24: 203-206.

50. Chroneos ZC, Jagannath C. 2012. Immunoregulatory Role of GM-CSF in Pulmonary Tuberculosis. INTECH Open Access Publisher, Croatia.

51. Nelson BH. 2004. IL-2, regulatory T cells, and tolerance. J. Immunol. 172: 3983-3988.

52. Johnson BJ, Ress SR, Willcox P, Pati BP, Lorgat F, Stead P, et al. 1995. Clinical and immune responses of tuberculosis patients treated with low-dose IL-2 and multidrug therapy. Cytokines Mol. Ther. 1: 185-196.

53. Johnson BJ, Bekker LG, Rickman R, Brown S, Lesser M, Ress S, et al. 1997. rhuIL-2 adjunctive therapy in multidrug resistant tuberculosis: a comparison of two treatment regimens and placebo. Tuber. Lung Dis. 78: 195-203.

54. Wallis RS, van Vuuren C, Potgieter S. 2009. Adalimumab treatment of life-threatening tuberculosis. Clin. Infect. Dis. 48: 1429-1432.

55. Rossi JF, Lu ZY, Jourdan M, Klein B. 2015. Interleukin-6 as a therapeutic target. Clin. Cancer Res. 21: 1248-1257.

56. Okada M, Kita Y, Kanamaru N, Hashimoto S, Uchiyama Y, Mihara M, et al. 2011. Anti-IL-6 receptor antibody causes less promotion of tuberculosis infection than anti-TNF-alpha antibody in mice. Clin. Dev. Immunol. 2011: 404929.

57. Datta M, Via LE, Kamoun WS, Liu C, Chen W, Seano G, et al. 2015. Anti-vascular endothelial growth factor treatment normalizes tuberculosis granuloma vasculature and improves small molecule delivery. Proc. Natl. Acad. Sci. USA 112: 1827-1832.

58. Zumla A, Rao M, Wallis RS, Kaufmann SH, Rustomjee R, Mwaba P, et al. 2016. Host-directed therapies for infectious diseases: current status, recent progress, and future prospects.
Lancet Infect. Dis. 16: e47-e63.

59. Podder B, Jang WS, Nam KW, Lee BE, Song HY. 2015. Ursolic acid activates intracellular killing effect of macrophages during Mycobacterium tuberculosis infection. J. Microbiol. Biotechnol. 25: 738-744.

60. Flores-Villalva S, Rogriguez-Hernandez E, Rubio-Venegas $Y$, Canto-Alarcon JG, Milian-Suazo F. 2015. What can proteomics tell us about tuberculosis? J. Microbiol. Biotechnol. 25: 1181-1194.

61. Tiwari B, Soory A, Raghunand TR. 2014. An immunomodulatory role for the Mycobacterium tuberculosis region of difference 1 locus proteins PE35 (Rv3872) and PPE68 (Rv3873). FEBS J. 281: 1556-1570.

62. Yang CS, Yuk JM, Lee YH, Jo EK. 2015. Toxoplasma gondii GRA7-induced TRAF6 activation contributes to host protective immunity. Infect. Immun. 84: 339-350.

63. Koh HJ, Kim YR, Kim JS, Yun JS, Jang K, Yang CS. 2017. Toxoplasma gondii GRA7-targeted ASC and PLD1 promote antibacterial host defense via PKCalpha. PLoS Pathog. 13: e1006126.

64. Pedral-Sampaio DB, Netto EM, Brites C, Bandeira AC, Guerra C, Barberin MG, et al. 2003. Use of Rhu-GM-CSF in pulmonary tuberculosis patients: results of a randomized clinical trial. Braz. J. Infect. Dis. 7: 245-252.

65. Wallis RS. 2005. Reconsidering adjuvant immunotherapy for tuberculosis. Clin. Infect. Dis. 41: 201-208.

66. Phillips BL, Mehra S, Ahsan MH, Selman M, Khader SA, Kaushal D. 2015. LAG3 expression in active Mycobacterium tuberculosis infections. Am. J. Pathol. 185: 820-833.

67. Postow MA, Callahan MK, Wolchok JD. 2015. Immune checkpoint blockade in cancer therapy. J. Clin. Oncol. 33: 1974-1982.

68. Parida SK, Madansein R, Singh N, Padayatchi N, Master I, Naidu K, et al. 2015. Cellular therapy in tuberculosis. Int. J. Infect. Dis. 32: 32-38. 